\title{
EFFICACY OF SCALP COOLING ON THE PREVENTION OF ALOPECIA IN CANCER PATIENTS UNDERGOING ADJUVANT CHEMOTHERAPY
}

\author{
${ }^{1}$ Hanan Mesbah Mohammed; ${ }^{2}$ Amira Ahmed Hassanen; ${ }^{3}$ Hanan \\ Mohammed MohammedSolimanand ${ }^{4}$ Mohammed Saad El-ashery \\ ${ }^{1}$ B.Sc, Mansoura University; ${ }^{2}$ Assist Professor of Medical-Surgical Nursing, Faculty of Nursing, \\ Mansoura University; ${ }^{3}$ Lectrureof Medical-Surgical Nursing, Faculty of Nursing, Mansoura \\ University; ${ }^{4}$ Assist Professor of Clinical Oncology and Nuclear Medicine, Faculty of Medicine, \\ Mansoura University. \\ E-mail of corresponding author: Hananmesbah2005@gmail.com
}

\begin{abstract}
:
Background: Alopecia is a distressing side effect for patients undergoing chemotherapy and occasionally can lead to refusal of treatment. Scalp cooling is a method of preventing chemotherapy-induced alopecia.The aim of study: to determine the efficacy of scalp cooling on the prevention of alopecia in cancer patients undergoing adjuvant chemotherapy. Materials and methods: The study design used was a quasi experimentalresearch design. A purposive sample of 60 adult female patients, age ranged 18-60 years old, with cancer and scheduled to be treated with adjuvant chemotherapy for the first time after curative surgery who met the inclusion criteria it will be divided randomly 30 subjects in study group and 30 subjects in control group, the study group were received scalp cooling while they receiving their chemotherapy cycle while the control group received the routine hospital care. Tool used divided into two parts including structure interview questionnaire and physiologic measurement tool of hair loss. The results of this study: Revealed that there is good hair preservation by $86.6 \%$ in the study group(scalp cooling group (SCG)) compared to $16.7 \%$ in the control group where $\mathrm{P}=.000$. Conclusion: The scalp cooling is effective in the prevention of chemotherapy induced alopecia in cancer patient. Recommendation: the scalp cooling is effective and should be applied for cancer patient during chemotherapy cycles thus the scalp cooling system should be available in the governmental hospitals and the women with cancer who take adjuvant chemotherapy should be encouraged to use scalp cooling to reduce total alopecia. Further psychological, clinical, and biological research is needed to improve the effect, tolerance, time, and side effect of the cooling procedure.
\end{abstract}

Key words: Alopecia, chemotherapy, scalp cooling.

\section{Introduction:}

Cancer is the first leading cause of death group worldwide and accounted for 7.6 million deaths (around 13\% of all deaths) in 2013. The main types of cancer are: Lung (1.3 million deaths/year), Stomach (803,000 deaths), Colorectal (639,000 deaths), Liver (610,000 deaths), Breast (519,000 deaths). More than $70 \%$ of all cancer deaths occurred in low- and middle-income countries. Deaths from cancer worldwide are projected to continue rising, with an estimated 11.5 million deaths in 2030. It affects all races and age groups, although it is more prevalent in the elderly and in certain geographical regions $^{(1)}$. 
Cancer is a major public health problem in the United States and many other parts of the world. One in 4 deaths in the United States is due to cancer. A total of $1,660,290$ new cancer cases and 580,350 cancer deaths are projected to occur in the United States in 2013. Incidence of cancer in Europe and the United States amounting to 5 times happen in Egypt, there are 100 to 200 new cases each year for every one hundred thousand Egyptian citizen, while the United States and European countries to have 400 to 500 new cases per one hundred thousand citizens, and either states Arab approaching cancer incidence rates from Egypt these may be due to regular check up in industry countries than these in Egypt, the statistical record of oncology center at mansoura university illustrate that 12.576 patients are diagnosed with cancer in the year $2013^{(2)}$.

Cancer is a group of diseases characterized by uncontrolled growth and spread of abnormal cells. If the spread is not controlled, it can result in death. Cancer is caused by both external factors (tobacco, infectious organisms, chemicals, and radiation) and internal factors (inherited mutations, hormones, immune conditions, and mutations that occur from metabolism). These causal factors may act together or in sequence to initiate or promote the development of cancer. Ten or more years often pass between exposure to external factors and detectable cancer. Cancer is treated with surgery, radiation, chemotherapy, hormone therapy, biological therapy, and targeted therapy ${ }^{(3)}$.

Chemotherapy, the treatment of cancer with chemical agents, is used to cure and to increase survival time. It has some selectivity for killing cancer cells over normal cells. This killing effect on cancer cells is related to the ability of chemotherapy to damage DNA and interfere with cell division. Tumors with rapid growth are most sensitive to chemotherapy $^{(4)}$.

Damage to normal cells result in chemotherapy toxicities and side effects, it can be seen that those actively dividing tissues such bone marrow, hair follicles and gastrointestinal mucosa are most vulnerable. Side effects of chemotherapy range from mild, like non-specific tiredness to lifethreatening as in neutropenic fever ${ }^{(5)}$.

Chemotherapeutic agents have the ability to kill dividing cells, without affecting normal cells that are in a resting stage. Since most cells in the human body are in a resting stage at any given moment, and cancer cells are often in a dividing stage, cancer cells are more susceptible to damage than healthy cells. However, certain healthy cell types in the human body also multiply quickly, such as the blood cells forming in the bone marrow and hair follicles. These healthy cells are also affected by chemotherapy and this leads to side effects such as fatigue, nausea, and hair loss (alopecia) ${ }^{(6)}$.

Cancer patients often experience hair loss as one of the most 
distressing side effects associated with chemotherapy treatments. Hair loss can cause emotional disturbances, i.e., sadness, shame and anger. Their hair style can be an important part of the patients' personal identity, and hair loss may have a negative impact on the patients' body image, self-confidence, sexuality and social relationships. In addition, hair loss is such a visible side effect that it constantly reminds the patient of the disease and the treatment $^{(7)}$.

Hair loss may be more threatening for women, perhaps because women's hair is regarded as an indicator of personality, attractiveness and femininity. Forty-seven percent of female cancer patients consider hair loss to be the most traumatic aspect of chemotherapy and $8 \%$ would even decline treatment for fear of this impending side-effect. Therefore, the effect of chemotherapy induced hair loss on patients is of minor concern to nurses and physicians. However, for patients, chemotherapy induced hair loss is one of the most feared side effects of cancer therapy. Although not highly detrimental to physical health, hair loss can be psychologically devastating and can even lead some patients to reject potentially curative treatment $^{(8)}$.

Chemotherapy-induced alopecia (CIA) is a frequent toxicity and arguably the most feared side effect of cancer chemotherapy. The incidence of Chemotherapy-induced alopecia is approximately $65 \%$ of all patients. Chemotherapy-induced alopecia could be easily noticeable by self and others in a relative short time, thus it is linked with having cancer and chemotherapy. Chemotherapy-induced alopecia (CIA) compromises patient quality of life, especially for female and children, leading to poor therapeutic outcome. Despite significant progresses and substantial efforts in Chemotherapyinduced alopecia research and development, no reliable and effective preventive treatment has become available. Chemotherapy causes structural damage of human scalp hairs. The effects may vary from altered hair appearance, decreased rate of hair growth, partial or complete hair loss (alopecia) ${ }^{(9)}$.

Scalp cooling is the most effective method to prevent Chemotherapyinduced alopecia (CIA). CIA may be prevented by scalp cooling prior to, during and sometime after chemotherapy infusion. Scalp cooling has been practiced since the 1970s. In currently used chemotherapies scalp cooling equipment prevents severe hair loss in about half of the patients. The mechanism of scalp cooling to prevent alopecia is based on the theory that cooling of scalp skin during chemotherapy infusion reduces blood flow, and thus there is less uptake of drug in the hair follicles. Cooling of the scalp skin can also reduce local tissue metabolism. It seems there are very many factors which influence the effectiveness of scalp cooling to prevent alopecia as the differences in the doses and combinations of chemotherapeutic agents, the cooling time, coolingtemperature, the condition of the hair, and the cooling device may also be variable. Therefore, the aim of this study is to 
Hanan Mesbah Mohammed et. al.

determine the efficacy of scalp cooling on the prevention of alopecia in cancer patients undergoing adjuvant chemotherapy $^{(10,11)}$.

\section{Aim of study}

The aim of this study is to determine the efficacy of scalp cooling on the prevention of alopecia in cancer patients undergoing adjuvant chemotherapy.

\section{Research hypothesis}

There is a highly significant difference between study group and control group as patients who practice scalp cooling intervention (study group) have less hair loss than those who don't use it (control group).

\section{Research Question:}

What is the efficacy of scalp cooling on the prevention of alopecia in cancer patients undergoing adjuvant chemotherapy?

\section{Materials and method}

\section{Materials:}

Design: A quasi experimental research design was followed.

Setting of the study: This study was conducted at the Oncology Center in Mansoura University Hospital.

Subjects:A purposive sample of 60 adult female patients,age ranged 18-60 years old, with cancer and scheduled to be treated with adjuvant chemotherapy for the first time after curative surgery who met sampling criteria recruited for this study was calculated by statistical equation; using EPI info program version 6.02 after taking into consideration the clinical incidence of 33.3 from the hospital record with the study power $80 \%$, confidence interval of $95 \%$ and relative precision $15 \%$, it will be divided randomly 30 subjects in study group (Scalp cooling group (SCG)) and 30 subjects in control group., the study group were received scalp cooling while they receiving their chemotherapy cycle while the control group received the routine hospital care, were selected from the above mentioned setting.

\section{Tools used in the study:}

\section{Tool I: structured interview questionnaire sheet}

A structured questionnaire was developed and tested by the researcher after extensive review of related literature. It was written in simple Arabic language this tool consists of five parts:

\section{Part 1:}

It includes questions related to the study subjects' socio-demographic data includeas age, marital status, employment status, residence and level of education.

\section{Part 2:}

Cover clinical data and medical history as date of admission, stage of disease, any prescribed medication, type of operation and past medical history.

\section{Part 3:}

Was used to identify data about hair loss and scalp cooling condition such as causes of hair loss, grades of hair loss, and presence of other scalp problems. 
Part 4:

Cover data about scalp cooling as how, 1 . when and who will perform scalp cooling.

Part 5:

Include data to evaluate the Side effect of scalp cooling as feeling cold, need blanket for warmth, had headache and feeling boring.

Tool II: Physiologic measurement tool for hair loss by using WHO grading system of hair loss at each cycle of chemotherapy.

It was developed by WHO and it was used in this study to assess thePhysiologic measurement for hair loss during each cycle of chemotherapy. The scale is a 5-point scale ranging from 0 (Not significant hair loss) to 4 (Total alopecia).The patient's head is observed, measured pre and after each cycle and compared with the previous cycle . The difference pre and after each cycle is ranked according to WHO criteria and the difference between the current cycle and the previous cycle measurement is ranked according to WHO criteria.

\section{WHO criteria of hair loss:-}

Grade 0 Not significant hair loss.

Grad 1 Minor hair loss, not requiring a wig.

Grade 2 Moderate hair loss, but not requiring a wig.

Grade 3 sever hair loss requiring a wig.

Grade 4 Total alopecia.

\section{Methods:}

An official permission was taken from the research ethics committee of the faculty of nursing at Mansoura University to the director of Oncology Center at Mansoura university hospital, to conduct the study after explaining its purposeas well as its expected outcomes.

2. The tool was developed by the researcher after reviewing the relevant literature and tested for its validity byjury of 8expertises in the field.

3. Pilot study was conducted on $10 \%$ of total number of female patients with cancer and undergoing adjuvant chemotherapy to test the validity and reliability of the tools they were then excluded from the study. Reliability test was made by using Cronbach's $($ alpha $=.85)$

\section{Ethical consideration:}

Prior to the study, verbal consent was obtained from each participating patient enrolment in to the study after clarification of the nature and purpose of the study. The investigator emphasized that participation is absolutely voluntary and confidential. Anonymity, privacy, safety and confidentiality were absolutely assured throughout the whole study. Each participant has the right to withdraw from the study at any time.

\section{Handling and analysis of data:}

The raw data were coded and entered into SPSS system files (SPSS package version 18). Analysis and interpretation of data were conducted.The following statistical measures were used: 
- Descriptive statistics including frequency, distribution, mean, and standard deviation were used to describe different characteristics.

- Kolmogorov - Smirnov test was used to examine the normality of data distribution.

- Univariate analyses using ChiSquare test was used to test the significance of results of qualitative variables.

- Linear correlation was conducted to show correlation between knowledge, attitude and practice scores among the studied health care workers.

- The significance of the results was at the $5 \%$ level of significance.

\section{Results}

Table (1): This table shows sociodemographic data for the women with cancer and undergoing adjuvant chemotherapy that exactly half $(50.0 \%)$ and less than half $(43.3 \%)$ of control and study group (scalp cooling group (SCG)) their age ranged from 40-49 years old in both groups respectively. Two thirds of the women in both groups (control group and study group) were married (73.3\%) and $(76.7 \%)$, respectively. As regard to residence exactly half of control group live in rural area and $50 \%$ live in urban area but in study group above half of the sample live in rural area $(56.7 \%)$ and only $(43.3 \%)$ live in urban area. In relation to educational level most of the women in control group (53.3\%) and two thirds of study group sample $(70.0 \%)$ have secondary education. Majority of both groups (control group and study group) $90.0 \%$ and $86.7 \%$ respectively, live with family. In relation to occupation there were $70.0 \%$ from the women in control group and $60.0 \%$ in study group were housewives. There is no significant difference between control group \&study group regarding sociodemograghic data $(\mathrm{P}>0.05)$. In relation to their treatment most of them were treated with FAC (Floruracil Adriamycin

Cyclophosphamide \{Endoxan\})

$(56.7 \%$ and $50 \%)$ for the control group and study (scalp cooling group (SCG)) group respectively. In relation to the operation type there were; $(3.3 \%, 0 \%)$ who undergoing cervectomy, for the control group and study group respectively, and nearly half (46.7\%) who undergoing mastectomy, for the control group and study group. $(\mathrm{P}>0.05)$ 
EFFICACY OF SCALP COOLING ON THE PREVENTION OF etc...

Table (1): Sociodemograghic data of the studied group

\begin{tabular}{|c|c|c|c|c|c|c|}
\hline \multirow[t]{2}{*}{ Sociodemograghic data } & \multicolumn{2}{|c|}{$\begin{array}{c}\text { Control group } \\
(\mathrm{N}=\mathbf{3 0})\end{array}$} & \multicolumn{2}{|c|}{$\begin{array}{c}\text { Study group } \\
(\mathrm{No}=\mathbf{3 0})\end{array}$} & \multirow[t]{2}{*}{$\mathbf{X}^{2}$} & \multirow{2}{*}{$\begin{array}{c}P \text { - } \\
\text { value }\end{array}$} \\
\hline & No & $\%$ & No & $\%$ & & \\
\hline $\begin{array}{l}\text { Age grouping:- } \\
18<39 \\
40<49 \\
50<60\end{array}$ & $\begin{array}{c}6 \\
15 \\
9\end{array}$ & $\begin{array}{l}20.0 \% \\
50.0 \% \\
30.0 \%\end{array}$ & $\begin{array}{c}12 \\
13 \\
5\end{array}$ & $\begin{array}{l}40.0 \% \\
43.3 \% \\
16.7 \%\end{array}$ & $\begin{array}{c}3.28 \\
6\end{array}$ & .193 \\
\hline $\begin{array}{l}\text { Marital status:- } \\
\text { Single } \\
\text { Married } \\
\text { Widow } \\
\text { Divorced }\end{array}$ & $\begin{array}{c}2 \\
22 \\
4 \\
2\end{array}$ & $\begin{array}{c}6.7 \% \\
73.3 \% \\
13.3 \% \\
6.7 \%\end{array}$ & $\begin{array}{c}1 \\
23 \\
3 \\
3\end{array}$ & $\begin{array}{c}3.3 \% \\
76.7 \% \\
10.0 \% \\
10.0 \%\end{array}$ & .698 & .874 \\
\hline $\begin{array}{l}\text { Residence } \\
\text { Rural } \\
\text { Urban }\end{array}$ & $\begin{array}{l}15 \\
15\end{array}$ & $\begin{array}{l}50.0 \% \\
50.0 \% \\
\end{array}$ & $\begin{array}{l}17 \\
13 \\
\end{array}$ & $\begin{array}{l}56.7 \% \\
43.3 \% \\
\end{array}$ & .268 & .605 \\
\hline $\begin{array}{l}\text { Educational level:- } \\
\text { Read and write } \\
\text { secondary education } \\
\text { Academic education }\end{array}$ & $\begin{array}{c}10 \\
16 \\
4\end{array}$ & $\begin{array}{l}33.3 \% \\
53.3 \% \\
13.3 \%\end{array}$ & $\begin{array}{c}2 \\
21 \\
7\end{array}$ & $\begin{array}{c}6.7 \% \\
70.0 \% \\
23.3 \%\end{array}$ & $\begin{array}{c}6.82 \\
7\end{array}$ & $.033 \%$ \\
\hline $\begin{array}{l}\text { Living status } \\
\text { Live with family } \\
\text { Live alone } \\
\end{array}$ & $\begin{array}{c}27 \\
3 \\
\end{array}$ & $\begin{array}{l}90.0 \% \\
10.0 \% \\
\end{array}$ & $\begin{array}{c}26 \\
4 \\
\end{array}$ & $\begin{array}{l}86.7 \% \\
13.3 \% \\
\end{array}$ & .162 & .688 \\
\hline $\begin{array}{l}\text { Occupation :- } \\
\text { Student } \\
\text { Employee } \\
\text { House wife } \\
\text { Retired }\end{array}$ & $\begin{array}{c}1 \\
7 \\
21 \\
1\end{array}$ & $\begin{array}{c}3.3 \% \\
23.3 \% \\
70.0 \% \\
3.3 \%\end{array}$ & $\begin{array}{c}0 \\
11 \\
18 \\
1\end{array}$ & $\begin{array}{c}0 \% \\
36.7 \% \\
60.0 \% \\
3.3 \%\end{array}$ & $\begin{array}{c}2.12 \\
0\end{array}$ & .548 \\
\hline $\begin{array}{l}\text { Type of cancer's drugs } \\
\text { Taxol-carpolinate } \\
\text { FAC(Floruracil-Adriamycin- } \\
\text { Cyclophosphamide }\{\text { Endoxan }\}) \\
\text { Foulox }\end{array}$ & $\begin{array}{c}5 \\
17 \\
\\
8\end{array}$ & $\begin{array}{l}16.7 \% \\
56.7 \% \\
26.7 \%\end{array}$ & $\begin{array}{c}5 \\
15 \\
10\end{array}$ & $\begin{array}{l}16.7 \% \\
50.0 \% \\
33.3 \%\end{array}$ & .347 & .841 \\
\hline $\begin{array}{l}\text { Operation type } \\
\text { Ovariectomy } \\
\text { Cervectomy } \\
\text { Coleictomy } \\
\text { Hysterectomy } \\
\text { Mastectomy }\end{array}$ & $\begin{array}{l}5 \\
1 \\
8 \\
2 \\
14\end{array}$ & $\begin{array}{l}16.7 \% \\
3.3 \% \\
26.7 \% \\
6.7 \% \\
46.7 \%\end{array}$ & $\begin{array}{l}5 \\
0 \\
10 \\
1 \\
14\end{array}$ & $\begin{array}{l}16.7 \% \\
0 \% \\
33.3 \% \\
3.3 \% \\
46.7 \%\end{array}$ & $\begin{array}{l}1.55 \\
6\end{array}$ & .817 \\
\hline
\end{tabular}

Table (2): Represents comparison between control group and study (SCG) group regarding alopecia questions that all women $(100 \%)$ in control group and the majority of the women $\quad(96.7 \%)$ in the studygroup(SCG) were suffered from hair loss, and all the women (100\%) in both groups suffering hair loss more than a month. There is no significant difference between the study group (SCG) \& the control group regarding alopecia questions $(\mathrm{P}<0.05)$.As regard to the degree of hair loss according to 
Hanan Mesbah Mohammed et. al.

WHO scaling system for hair loss there is highly significance difference between the two groups regarding degree of hair loss $(\mathrm{p}=.000)$ as in the control group there were $(46.7 \%)$ suffering total alopecia in comparison to study group (SCG) there were
(3.3\%) suffering total alopecia .This means that the study group (scalp cooling group) suffered less hair loss after receiving scalp cooling than the control group who receive the routine hospital care.

Table (2): comparison between control group and study group regarding alopecia questions

\begin{tabular}{|c|c|c|c|c|c|c|}
\hline \multirow[t]{2}{*}{ Alopecia questions } & \multicolumn{2}{|c|}{$\begin{array}{c}\text { Control } \\
\text { group } \\
(\mathrm{N}=\mathbf{3 0})\end{array}$} & \multicolumn{2}{|c|}{$\begin{array}{c}\text { Study group } \\
(\text { No }=30)\end{array}$} & \multirow[t]{2}{*}{$X^{2}$} & \multirow[t]{2}{*}{$P$ - value } \\
\hline & No & $\%$ & No & $\%$ & & \\
\hline $\begin{array}{l}\text { Suffering from hair loss:- } \\
\text { Yes } \\
\text { No }\end{array}$ & $\begin{array}{c}30 \\
0\end{array}$ & $\begin{array}{c}100.0 \\
\% \\
.0 \% \\
\end{array}$ & $\begin{array}{c}29 \\
1\end{array}$ & $\begin{array}{c}96.7 \% \\
3.3 \%\end{array}$ & 1.017 & .313 \\
\hline$\frac{\text { Time of hair loss:- }}{\text { More than a month }}$ & 30 & $\begin{array}{c}100.0 \\
\%\end{array}$ & 30 & $\begin{array}{c}100.0 \\
\% \\
\end{array}$ & - & - \\
\hline $\begin{array}{l}\text { Degree of hair loss:- } \\
\text { 0-Not significant hair loss } \\
\text { 1-Minor hair loss not } \\
\text { requiring a wig } \\
\text { 2-Moderate hair loss not } \\
\text { requiring a wig } \\
\text { 3-sever hair loss, requiring a } \\
\text { wig } \\
\text { 4- Total alopecia }\end{array}$ & $\begin{array}{l}0 \\
0 \\
4\end{array}$ & $\begin{array}{c}0 \% \\
0 \% \\
16.7 \% \\
\\
40.0 \% \\
43.3 \%\end{array}$ & $\begin{array}{c}1 \\
19 \\
6\end{array}$ & $\begin{array}{c}3.3 \% \\
63.3 \% \\
20.0 \% \\
\\
10.0 \% \\
3.3 \%\end{array}$ & $\begin{array}{c}37.06 \\
7\end{array}$ & $.000 * *$ \\
\hline $\begin{array}{l}\text { Other scalp problems } \\
\text { before chemotherapy: } \\
\text { No }\end{array}$ & 30 & $\begin{array}{c}100.0 \\
\%\end{array}$ & 30 & $\begin{array}{c}100.0 \\
\%\end{array}$ & - & - \\
\hline
\end{tabular}

Table (3): Represents the prevalence of scalp cooling side effect, where $100 \%$ of study group(scalp cooling group) suffered from feeling cold and $70 \%$ needed blanket for warmth during doing this procedure. And
$100 \%$ are suffering from headache and feel boring 
EFFICACY OF SCALP COOLING ON THE PREVENTION OF etc...

Table (3):Prevalence of side effects of scalp cooling among scalp cooling group.

\begin{tabular}{|l|c|c|}
\hline \multirow{2}{*}{ Scalp cooling side effects } & \multicolumn{2}{|c|}{$\begin{array}{c}\text { Study group } \\
\text { (No =30) }\end{array}$} \\
\cline { 2 - 3 } & No & \% \\
\hline Feeling cold:- & 30 & $100.0 \%$ \\
Yes & 0 & $0 \%$ \\
No & 21 & $70.0 \%$ \\
\hline Blanket for warmth:- & 9 & $30.0 \%$ \\
\hline Yes & 30 & $100.0 \%$ \\
No & 0 & $0 \%$ \\
\hline Headache :- & & $100.0 \%$ \\
\hline Yes & 30 & 0 \\
\hline No & 0 & \\
\hline Feeling boring:- & & \\
Yes & & \\
\hline
\end{tabular}

Table (4): Represents comparison between control group and study group(SCG) in grades of hair loss before the first cycle and after the six cycle of chemotherapy there were $(63.3 \% \& 0 \%)$ have grade1 from the study group (SCG)andcontrol group respectively. While there were
$(43.3 \% \& 3.3 \%)$ have grade 4 (total alopecia) from the control group and study group(SCG) respectively after the six cycle of chemotherapy. There is highly significance difference between the two groups regarding grades of hair loss. $\mathrm{P}<.05$

Table (4): Comparison between control group \&study group (scalp cooling group) in grades of hair loss according to WHO before the first cycle and after the six cycle of chemotherapy.

\begin{tabular}{|c|c|c|c|c|c|c|c|c|c|c|c|c|}
\hline \multirow{3}{*}{$\begin{array}{l}\text { Grades of } \\
\text { hair loss }\end{array}$} & \multicolumn{4}{|c|}{ Control group } & \multicolumn{4}{|c|}{ Study group (SCG) } & \multicolumn{2}{|l|}{$\mathrm{X}^{2}$} & \multicolumn{2}{|c|}{$P$ - value } \\
\hline & \multicolumn{2}{|c|}{$\begin{array}{c}\text { Before cycle } \\
1\end{array}$} & \multicolumn{2}{|c|}{ After cycle 6} & \multicolumn{2}{|c|}{$\begin{array}{l}\text { Before } \\
\text { cycle } 1\end{array}$} & \multicolumn{2}{|c|}{ After cycle 6} & \multirow[t]{2}{*}{$\begin{array}{l}\text { Before } \\
\text { cycle } 1\end{array}$} & \multirow[t]{2}{*}{$\begin{array}{c}\text { After } \\
\text { cycle } 6\end{array}$} & \multirow{2}{*}{$\begin{array}{c}\text { Befor } \\
\text { e cycle } \\
1\end{array}$} & \multirow[t]{2}{*}{$\begin{array}{c}\text { After } \\
\text { cycle } 6\end{array}$} \\
\hline & $\begin{array}{l}\mathbf{N} \\
\mathbf{0}\end{array}$ & $\%$ & $\begin{array}{l}\mathbf{N} \\
\mathbf{0}\end{array}$ & $\%$ & No & $\%$ & No & $\%$ & & & & \\
\hline 0 & 30 & $100 \%$ & 0 & $0 \%$ & 30 & 100 & 1 & $3.3 \%$ & 1.017 & 35.777 & .313 & $.000 * *$ \\
\hline 1 & 0 & $0 \%$ & 0 & $0 \%$ & 0 & & 19 & $63.3 \%$ & & & & \\
\hline 2 & & & 5 & $16.7 \%$ & & & 6 & $20.0 \%$ & & & & \\
\hline 3 & & & 12 & $40.0 \%$ & & & 3 & $10.0 \%$ & & & & \\
\hline 4 & & & 13 & $43.3 \%$ & & & 1 & $3.3 \%$ & & & & \\
\hline
\end{tabular}


Table (5):Represents the relation between the type of chemotherapy and grades of hair loss after the sixth cycle of chemotherapy in both control group and study group (SCG) that there were $40 \%$ from the women treated withTaxol-carpolinatein study group have gradeI hair loss and also $40 \%$ have grade II hair loss while $60 \%$ from the women who treated with taxolcarpolinate in the control group have grade III hair loss. In relation to the women treated withFAC(FloururacilAdriamycin-

Table (5) The relation between grades of hair loss and type of chemotherapy after the six cycle of chemotherapy among study group (scalp cooling group) and control group.

\begin{tabular}{|c|c|c|c|c|c|c|c|c|c|c|c|c|c|c|c|c|}
\hline \multirow{3}{*}{$\begin{array}{c}\text { Grades } \\
\text { of hair } \\
\text { loss }\end{array}$} & \multicolumn{6}{|c|}{ Type of chemotherapy in SCG group } & \multicolumn{6}{|c|}{ Type of chemotherapy in control group } & & & & \\
\hline & \multicolumn{2}{|c|}{$\begin{array}{c}\text { Taxol- } \\
\text { carpolinate }\end{array}$} & \multicolumn{2}{|c|}{$\begin{array}{c}\text { FAC(Floururacil- } \\
\text { Adriamycin- } \\
\text { Cyclophosphamide } \\
\text { \{Endoxan\}) } \\
\end{array}$} & \multicolumn{2}{|c|}{ Foulox } & \multicolumn{2}{|c|}{$\begin{array}{c}\text { Taxol- } \\
\text { carpolinate }\end{array}$} & \multicolumn{2}{|c|}{$\begin{array}{c}\text { FAC(Floururacil- } \\
\text { Adriamycin- } \\
\text { Cyclophosphamide } \\
\text { (Endoxan\}) } \\
\end{array}$} & \multicolumn{2}{|c|}{ Foulox } & \multicolumn{2}{|c|}{$\mathrm{X}^{2}$} & \multicolumn{2}{|c|}{$P$-value } \\
\hline & No & $\%$ & No & $\%$ & $\mathrm{~N}$ & $\%$ & No & $\%$ & No & $\%$ & No & $\%$ & SCG & Control & SCG & Control \\
\hline $\begin{array}{c}\text { Grade } \\
0\end{array}$ & 0 & $0 \%$ & 0 & $0 \%$ & 1 & $10.0 \%$ & - & - & - & - & - & - & & & & \\
\hline $\begin{array}{c}\text { Grade } \\
1\end{array}$ & 2 & $40.0 \%$ & 9 & $60.0 \%$ & 8 & $80.0 \%$ & - & - & - & - & - & - & & & & \\
\hline $\begin{array}{c}\text { Grade } \\
2\end{array}$ & 2 & $40.0 \%$ & 3 & $20.0 \%$ & 1 & $10.0 \%$ & 1 & $20.0 \%$ & 1 & $5.9 \%$ & 3 & $37.5 \%$ & 7.061 & 15.962 & .530 & $.003^{*}$ \\
\hline $\begin{array}{c}\text { Grade } \\
3\end{array}$ & 1 & $20.0 \%$ & 2 & $13.3 \%$ & 0 & $0 \%$ & 3 & $60.0 \%$ & 4 & $23.5 \%$ & 5 & $62.5 \%$ & & & & \\
\hline $\begin{array}{c}\text { Grade } \\
4\end{array}$ & 0 & $0 \%$ & 1 & $6.7 \%$ & 0 & $0 \%$ & 1 & $20.0 \%$ & 12 & $70.6 \%$ & 0 & $0 \%$ & & & & \\
\hline
\end{tabular}

Table (6):Represents the relation between age \& grades of hair loss after the 6th cycle among study group(scalp cooling group)(SCG) that all women whose age ranged from (18
Cyclophosphamide\{Endoxan\}) there were $60 \%$ from the women in study group(SCG)have grade I hair loss while in the control group there were $70.6 \%$ have grade IV hair loss. As regard to the women who treated with Floxthere were $80 \%$ from the women in the study group have grade I hair loss while $62.5 \%$ from the women in the control group have grade III. There were significance differences between the two groups in grades of hair loss in relation to type of chemotherapy 
EFFICACY OF SCALP COOLING ON THE PREVENTION OF etc...

loss. This means that there was a significance difference between younger age women (most of them have gradeI) \& the older age women (which they have gradeII,III,IV)and the grades of hair loss. $(\mathrm{P}<0.05)$

Table (6) Relation between age $\&$ grades of hair loss after $6^{\text {th }}$ cycle among study group (scalp cooling group).

\begin{tabular}{|c|c|c|c|c|c|c|c|c|}
\hline \multirow{3}{*}{$\begin{array}{c}\text { Grade } \\
\text { of hair } \\
\text { loss }\end{array}$} & \multicolumn{6}{|c|}{ Age } & \multirow{3}{*}{$\mathbf{X}^{2}$} & \multirow{3}{*}{$P$ - value } \\
\hline & \multicolumn{2}{|c|}{$18<39$} & \multicolumn{2}{|c|}{$40<49$} & \multicolumn{2}{|c|}{$50<60$} & & \\
\hline & No & $\%$ & No & $\%$ & No & $\%$ & & \\
\hline Grade 0 & 0 & $0 \%$ & 1 & $7.7 \%$ & 0 & $0 \%$ & & \\
\hline Grade 1 & 12 & $100 \%$ & 6 & $46.2 \%$ & 1 & $20.0 \%$ & 17.174 & $.028 *$ \\
\hline Grade 2 & 0 & $0 \%$ & 4 & $30.8 \%$ & 2 & $40.0 \%$ & & \\
\hline Grade 3 & 0 & $0 \%$ & 2 & $15.4 \%$ & 1 & $20.0 \%$ & & \\
\hline Grade 4 & 0 & $0 \%$ & 0 & $0 \%$ & 1 & $20 \%$ & & \\
\hline
\end{tabular}

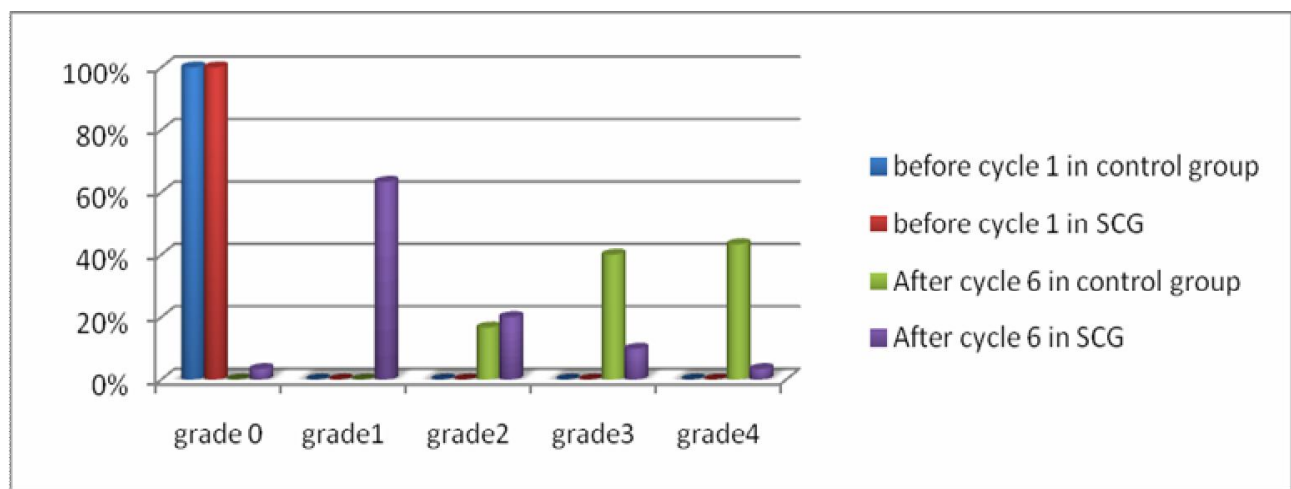

Fig (1) Comparison between control group \&study group (SCG) in grades of hair loss according to WHO before the first cycle and after the six cycle of chemotherapy. 


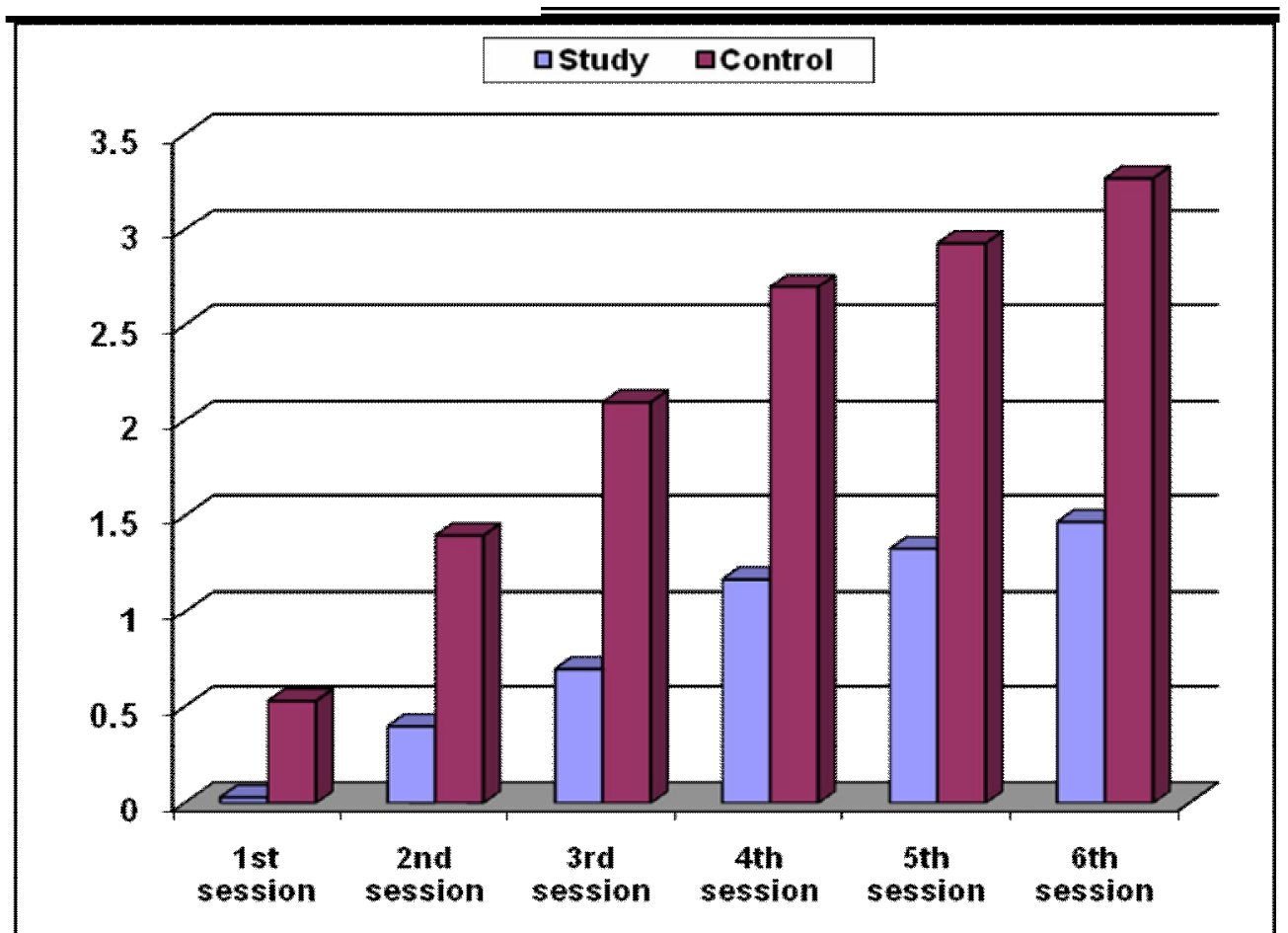

Fig (2) Comparison between the control and study group(SCG) in the six cycles of chemotherapy in relation to hair loss

\section{Discussion:}

Chemotherapy-induced hair loss occurs with an estimated incidence of $65 \%$. Forty-seven percent of female patients consider hair loss to be the most distressing side effect of chemotherapy and $8 \%$ would decline chemotherapy due to fears of hair loss. Chemotherapy-induced temporary hair loss is one of the most common and emotionally distressing side-effects of cancer therapy. Since about 1970, many preventive measures have been tried to reduce chemotherapy-induced alopecia thetourniquet, medicaments and scalp cooling. Currently, preventive measures mainlyfocuson scalp cooling ${ }^{(12,13)}$.

Discussion of the study results will cover five main areas; the first part concerned with representation of socio-demographic characteristics of the study group as patient's assessment regarding present medical history and health state. The second part concerned with the answer of the research question; it represents effectiveness of scalp cooling in prevention of hair loss according to WHO scaling system for hair loss. The third part concerned with the side effect of scalp cooling. The fourth part concerned with the effectiveness of scalp cooling with different types of chemotherapy. Finally the fifth part concerned with the relation between sociodemographic data and grades of hair loss.

\section{Part I: Sociodemographic characteristics}


The results of the current study revealed that less than half from the participant female in the study group and exactly half from theparticipant female in the control group their age ranged from 40 - 49 years old. Interestingly, in the same line, ${ }^{(14,15,16,17)}$ whofound thatmost of theparticipant patients in the study and control group their age ranged from $40-49$ years old.This may be due to females exposed to more stresses, nutritional deficiency, obesity and hormonal changes in that age.

In relation to marital status the majority of the women in the study group (SCG) and control group were married, this is consistent with ${ }^{(15,18,17)}$ who found that the majority of the study and control group were married. This may be due to as the women that included in the study from 18-60 years old "the productive life" so it is normally for the majority of them to be married. This may indicate that marriage associated problems may result in cancer either by increasing work load, responsibilities and stress.

In relation to educational level, more than two third of the study group and slightly more than one half of the control group had secondary education. This result consistent with $^{(15)}$ who has most of the patients with secondary education but contradict with ${ }^{(16)}$ who had the most of their participant patients with University education. This difference may be due to the difference between countries regarding awareness and culture. This level of education may affect the level of awareness and understanding regarding the preventive information of the cancer and also the importance of its early detection through the scheduled follow up.

The current study revealed that slightly more than one half of the study group (SCG) and one half of the control group reside rural areas and the majority of the women in both groups live with their family. This agrees with ${ }^{(17,18)}$ who found that most of patients reside rural areas and live with their family.

The women in the current study have different types of cancer and undergone the prescribed type of operation accordingly as slightly less than half from the study group (SCG) undergone mastectomy and the rest undergone different types of operations as; ovariectomy, coleictomy, hysterectomy and cervectomy from both groups. This result is agree with a study done by ${ }^{(19)}$ whohas their study patient undergone several type of operations as mastectomy, ovariectomy and colectomy. The result also supported by the study done by ${ }^{(20)}$ who has the studied patients undergone many types of cancer surgery as breast cancer, ovariecotomy and gastrointestinal operations but the majority of them have had operation due to breast cancer.

The result contradicts with the study result done by ${ }^{(15,17)}$ whose study group undergone mastectomy only. This mean that the author who stabilize the type of operation for the study group want to stabilize the type of chemotherapy and examine the effect of scalp cooling on that medication while who used several types of cancer operations want to examine the effect of scalp cooling on 
different types of chemotherapy used after these operations. Also the majority of patients had mastectomy because the studied sample were female, this finding was matched with the National Cancer Institute, which report that majority of breast cancer cases are females.

Most of the women in both groups were at the $2^{\text {nd }}$ stage of their disease, and also most of them complain the disease from 1-3 years in control group and study group (SCG). This result is agree withthe study done by ${ }^{(16)}$ whose patients in the study group with early stage of disease and the length of the disease occurs within 1-3 years in most of patients.

Both groups in the present study were treated with an intravenous (IV) chemotherapy drug regimen. The treatment schedule included six cycles of chemotherapy at intervals of 3 weeks.Including one of the following major alopeciacausingagents and these drugs were given according to the type of operation, as for women undergone ovariectomy take Taxol-carpolinate (paclitaxil), women undergone mastectomy, hysterectomy and cervectomy take FAC(5-FloruracilAdriamycin(Doxorubicin)-

Cyclophosphamide \{Endoxan\}) and for women undergone colectomy take Flox $(\mathrm{F}=$ Fluorouracil, $\mathrm{L}=$ Leucovorin , OX = Oxaliplatin ) thus most of them in both control group and scalp cooling group were treated with FAC (5-Floruracil - Adriamycin (Doxorubicin)- Cyclophosphamide $\{$ Endoxan\}).

This result is agreed with a study done by ${ }^{(20)}$ who had cancer patients participants receiving FAC, paclitaxil and docetaxel. The treatment schedule included six cycles of chemotherapy at intervals of 3 weeks.

This also, in the same line with ${ }^{(15)}$ whose patient were treated with FEC (5- Floruracil- EpirubcinCyclophosphamide $\{$ Endoxan\}). Also, agree with the results of ${ }^{(16)}$ who had the patients treated with doxorubicin, docetaxel and FEC. Also in agreement with the study result to ${ }^{(17)}$ who used the FAC regimen in the treatment of breast cancer patients. The treatment schedule included six cycles of chemotherapy at intervals of 3 weeks.

This disagrees with ${ }^{(21)}$ who used Docetaxel in the treatment of breast cancer. Also disagree with ${ }^{(22)}$ which had cancer patients participants receiving Adriamycin and vincristine, Taxotere(Docetaxel), Taxol and Adriamycin. These differences may be due to variation in the treatment regimen according to the hospital protocol in sequence with the operation type.

The study group in the present study was treated by scalp coolingduring administration of the chemotherapy by using scalp cooling machine (OrbisPaxman scalp cooling machine). It was applied to the scalp half hour before starting chemotherapy, during chemotherapy and an hour after accomplishing chemotherapy. Temperature kept at $3 \mathrm{C}^{\circ}$. This agree with the study done by ${ }^{(15,20)}$ who use the same cooling machine (OrbisPaxman) and is applied to the scalp before starting approximately 30 minutes prior to chemotherapy and must continue for 30 to 90 minutes after the conclusion 
EFFICACY OF SCALP COOLING ON THE PREVENTION OF etc...

of treatment but they were disagree in the temperatureon the surface of the scalp below which at $-18^{\circ} \mathrm{C}$. This difference in the utilized temperature may be due to the difference between countries in relation to atmosphere.

The result disagree with the result of the study done by ${ }^{(19,21,23)}$ who used penguin caps as scalp cooling device in which these caps need to be changed frequently during the administration of chemotherapy but agree with them in the cooling period and the cooling temperature as they apply the cooling caps half hour before starting chemotherapy, during chemotherapy and up to 90 minutes after accomplishing chemotherapy and the temperature of the cap had to be below $-25^{\circ} \mathrm{C}$.

The result also contradict with study result to ${ }^{(17)}$ whoused manual cooled caps at $8 \mathrm{c}^{\circ}$ and the caps remained on the scalp for 15 minutes only after infusion of chemotherapy. This difference may be due to the availability of the cooling system in the hospital or the facility to obtain the devices of scalp cooling to apply it.

It is important that the scalp remains cold during the time that the drugs causing alopecia are at their highest plasma concentration. Complexpharmacokinetic data are often involved when taking drug halflives into consideration. In theory, the scalp should remain cold until the level of active drug or its metabolites are reduced to sufficiently low levels in the plasma. However, data regarding the levels at which a drug no longer causes alopecia are often not available and therefore, recommendations for scalp-cooling times are often based upon past experience.

Part II: Effectiveness of scalp cooling in prevention of hair loss according to WHO scaling system for hair loss:

According to the aim of this study, determine the efficacy of scalp cooling on the prevention of alopecia in cancer patients undergoing adjuvant chemotherapy, the results of the current study revealed that after the last chemotherapy session there were a statistically highly significance improvement among study group (SCG) in comparison to control group regarding alopecia where $p$-value $=.000$ that there were success rate in the majority of patients in the study group who didn't need to wear a wig (grade 0,1,2) while in the control group there were above quarter who had the same grades. While in the control group the majority of patients were requiring to wear a wig (grade 3 , 4) in comparison to less quarter from the patients in the study group who need to wear a wig (grade 3, 4).

This result agreed with study done by ${ }^{(23)}$ who found that the most of patients in the study group (SCG) not required to wear a wig (grade $0,1,2$ ). $\&$ all of patients in the control group required to wear a wig (grade 3,4$)$.The result also agree with the result of the study done by ${ }^{(21,24)}$ who reported that there were success rate (grade 0, 1, 2)in mostly of cold caped patients (study group) didn't require to wear a wig .

The finding also supported by the study result of $(15,16)$ who found that there was success rate (grade 0,1 , 
2) in the majority of scalp cooled patients.

The study result also consistent with the study of ${ }^{(20)}$ who achieved success rate in half of the patients who didn't require to wear a wig (grade $0,1,2$ ).

But the finding is disagree with the result reported by ${ }^{(17)}$ who reported that the success rate only $(10 \%)$ from the scalp cooled patient that was nearly similar with the control group. This difference may be due to that the last author used manual caps kept at $8 \mathrm{c}^{\circ}$ and remained on the scalp for 15 minutes only after infusion of chemotherapy and the scalp cooling as reported by most references should be applied 30 minutes before starting chemotherapy and during infusion period and after accomplishing chemotherapy from 30-90 minutes and the cooling temperature should be kept below $-25 c^{\circ}$ as the current study and the supported authors utilize types of scalp cooling that deliver cooling to the scalp according to these references.

There were a statistically highly significance difference between study group (SCG)\& Control group regarding the grades of hair loss pvalue $=.000$ as a slightly more than half from patients who treated with scalp cooling (study group) had grade 1 hair loss while only (3.3\%) from them had grade 4 hair loss. On the other hand slightly less than half from of the patients on the control group who received routine hospital care had grade 3 , and also, slightly less than half from them had grade 4 hair loss.

In the same line ${ }^{(20)}$ reported that half of patients who treated with scalp cooling had grade 2 hair loss while in the control group the majority from them had grade ( $3 \& 4)$. Also, the result is supported by ${ }^{(23)}$ whoreported that nearly two third of patients in scalp cooled group (study group) had grade $(1 \& 2)$ while in the control group all of patients had grade $(3,4)$.

The result also in agreement with the result of study of ${ }^{(15)}$ who had nearly two third of patients in scalp cooled group (study group) had grade $(0,1)$. This may be due to the variation in the type of cooling system, cooling time and cooling temperature or variation in the chemotherapy (type, dose, time of infusion) or variation on patient himself as type of hair and age.

\section{Part IV: Side effect of scalp cooling.}

According to the finding of the present study the prevalence of scalp cooling side effect were: all scalp cooled patients(study group) suffered from feeling cold and the majority of them needed blanket for warmth during doing this procedure. And also, all of them were suffered from headache and feel boring. In the same line the result reported by ${ }^{(17,24)}$ whose scalp cooled patients (studygroup) suffered from headache, feel boring ,coldness and uncomfortable sensation during the scalp cooling procedure.

Also, in agreement with the study resultdone by ${ }^{(15)}$ who report that the side effect from scalp cooling (study ngroup) were, almost all of SCG suffering from pressure and tightness of scalp cooling caps, about half of them feeling cold, and only one third need blanket for warmth, also another one third suffering from headache and boredom. The result also consistent with the study of ${ }^{(16)}$ who report that most common side effects 
of scalp coolers are headache, a cold sensation in the skin of the scalp, and shivering. These side-effects were in general not serious. There were a few studies in which in more than $10 \%$ of the patient's side effects were reasons for stopping the cooling procedure.

This may be due to pressure and tightness of the scalp cooling caps which in the same instances lead to pain in the forehead leading to headache. Cooled caps temperature is kept below $-25 \mathrm{c}^{\circ}$ during the time of procedure which may take more than 2 hours this lead to feeling cold and feel boring.Scalp cooling can be a long and uncomfortable procedure and should not be offered to patients unless it is very likely to be beneficial.

Part III effectiveness of scalp cooling as regard to types of chemotherapy.

There is a significant improvement in alopecia in study group (SCG) who treated with Taxol-carpolinate compared to alopecia in the control group who treated with the same drug as the majority of women in study groupSCG had grade $(1,2)$ hair loss while the majority of women in the control group have grade $(3,4)$ hair loss. There were also significant improvement in alopecia in study group(SCG) who treated with FAC (Floururacil-Adriamycin-

Cyclophosphamide \{Endoxan\}) compared to alopecia in the control group who treated with the same drug as nearly more than half from the women instudy group(SCG) have grade 1 hair loss while in the control group about two third from the women have grade 4 hair loss. There were also, significant improvement in alopecia in study group (SCG) who treated with Flox compared to alopecia in the control group who treated with the same drug as the majority from the women in the study group (SCG) have grade I hair loss while nearly more than half from the women in the control group have grade 3 .

This shows that the quantity of hair loss is related to the type of chemotherapy as reported by the current study some medications lead to grade 4 hair loss as FAC and others lead to grade 3 hair loss as paclitaxil and FLOX. This affect the result of scalp cooling as the medication that leads to grade 4 has improvement in most of women while the medication that lead to grade 3 has improvement in the majority of women. This is due to the relation between the type of chemotherapy drug and its effect on hair.

This result supported by the result of ${ }^{(15)}$ who foundthat there were success rate in the majority of patients who treated with FEC regimen. Also confirmed with the result to ${ }^{(20)}$ who reported that the success rate in almost all of patients treated withdocetaxel and in the majority of patients who treated with paclitaxil but disagree with him in the result of FAC that he found the success rate was only on $8 \%$ of his patients.

Also, the result was agree with ${ }^{(16)}$ whose results reported that hair loss was avoided in all of patients given doxorubicin treatment, while hair loss is avoided in the majority of patients given docetaxel treatment, and in about two third of patients given FEC treatment, and also in about two third of patients given docetaxel followed by FEC. 
The findings also is in agreement with the result of the study done by the following authors; ${ }^{(25)}$ who use doxorubicin, vincristine, fluorouracil and methotrexate the hair is preserved in half in cooled caped patients(study group) while is preserved in less than quadrant in the control group who receive the routine hospital care, also ${ }^{(26)}$ who used cyclophosphamide, fluorouracil and methotrexate the hair is preserved in all cooled caped patients (study group) and in less than quadrant in the control group who receive the routine hospital care.

Our results also, in agreement withthe study of ${ }^{(19)}$ who found success rate in the majority of patients who treated with taxenes and in all of patients who treated with Etoposoidsor anthracyclines in scalp cooled patients (study group).

Also, the result supported by the result of ${ }^{(21)}$ who found success rate in nearly all of patients who treated with docetaxel in scalp cooling group and in $5 \%$ in the control group who treated with the same treatment. Also the result consistent with ${ }^{(23)}$ who achieve success rate in two third from patients treated with FEC in scalp cooling group while no patient in the control group preserved hair who treated with the same treatment. This may be due to the variation in the chemotherapy type, dose and frequency of chemotherapy infusion, the type of scalp cooling equipment and duration of scalp cooling itself.

In the current study part of the patients were given paclitaxel, which has a longer infusion time than docetaxel. In addition, in the other studies anthracyclines and taxanes were given concomitantly, while in the present study the patients received taxane and anthracycline treatments sequentially. So, the mentioned differences in administration may affect the infusion time and might partly explain the differences in the results.

Part VI :The relation between Sociodemographic characteristics and grades of hair loss.

There were a statistically significance difference regarding alopecia in younger age women than older age women The result of this study revealed that there was less hair loss in younger age than in older age as all of women whose age ranged from $(18-39)$ years old have grade I hair loss and nearly half from women aged from $(40-49)$ have grade I hair loss. Otherwise nearly half from women aged from $(50-60)$ have grade II hair loss and nearly half has grade 3,4 . This result is consistent with ${ }^{(15,17,27)}$ they also found that there were less hair loss in younger age than in older age. It is possibly due to that aged skin has a diminished coldinduced vasoconstriction and an agerelated decline in organ function may increase toxicity leading to higher chemotherapeutic concentrations in hair root cells during scalp cooling. Chemotherapeutics mainly affect anagen hairs, i.e. hair in the growth phase, and cause a sharp constriction of the hair shaft, where hairs may break. Therefore the reduced hair diameter at older age may also increase the risk of breakage.

Finally, based on the finding of the present study and most of the finding of the previous researches, the scalp 
cooling is effective in prevention of alopecia on cancer patients undergoing chemotherapy, the effectiveness of scalp cooling depend on many factors as chemotherapy (type, dose and frequency), the cooling system (type, cooling time, cooling duration) and factors in patient him as age.

\section{Conclusion:}

Based on the findings of the present study, it could be concluded that:

The scalp cooling is effective in the prevention of chemotherapy induced hair loss in cancer women scheduled to be treated with chemotherapy for the first time after curative surgery and free from metastasis while using OrbisPaxman scalp cooling machine at $-3^{\circ}$, and when it was applied to the scalp half hour before starting chemotherapy, during chemotherapy and an hour after accomplishing chemotherapy. Also the degree of hair loss was varied according to the type of chemotherapy regimen used in the treatment. There was less hair loss in younger age women than older age women. The majority of patients tolerate cooling very well and side-effects are not frequent and not serious. This answers the research question (what is the efficacy of scalp cooling on the prevention of alopecia on cancer patients undergoing adjuvant chemotherapy)

\section{Recommendation:}

Based upon the findings of the current study:

- The scalp cooling is effective and should be applied for cancer patient during chemotherapy cycles thus the scalp cooling system should be available in the governmental hospitals.

- The nurses in position to improve care of women who had chemotherapy induced alopecia so that they should be educated about how to apply the SC procedure and to encourage the cancer patients to have this procedure.

- It is also recommended that the women with cancer and undergone adjuvant chemotherapy should be encouraged to use scalp cooling to reduce alopecia since the pharmacological intervention remains uncertain.

- Further researches should be done to evaluate the effectiveness of scalp cooling when using the combination chemotherapy with high doses and with a lot of chemotherapy cycles.

- Also researches should be done to determine the extent of scalp skin metastasis while using the scalp cooling.

- The following most important associated factors should be studied ; post infusion cooling time (PICT) which may imply shortening the discomfort and the extra time in the hospital following the chemotherapy cycle. Scalp cooling research on dose-response relationship (cooling temperature and time) needs to be conducted more efficiently. Also Quality and growth of hair during and after scalp cooling.

\section{Acknowledge:}

We would to thank all hospital staff that assisted us in this study

\section{References:}


1- Burke, K., Lemone, P., \&MohnBrown, E., (2007): Medical Surgical Nursing Care, $2^{\text {nd }}$ ed., Canada,Pearson Co., pp 863-870.

2- Drlan, B. \& Dame, J. \& Jo, R.(2012): Adult Nursing Practice. $1^{\text {st }}$ ed ; Oxford co., pp; 51-56.

3- Donna D, Linda M, (2013):Medical Surgical Nursing, Care of patient with cancer, $7^{\text {th }}$ ed, Elsevier co., pp 409- 423.

4- Wilson, S. F., \& Giddens, J. F. (2009): Health Assessment for Nursing Practice. $4^{\text {th }}$ ed, Lippincott Williams\& Wilkins co., pp; 270278.

5- Grana

G.,

Chemotherapy.

(2008): http:www.cancer .org.

6- Carpenter, C., Griggs, R., \&Loscalzo, J., (2008): CECIL Essentials of medicine, $7^{\text {th }}$ ed., USA,Saunders Co., pp 533-545.

7- Lemone, P.,Burke, K., (2008): Medical Surgical Nursing, Critical thinking in client care, $1^{\text {st }}$ ed., Canada, Pearson Co., pp 369370 .

8- Janseen, F.P., (2007): The relationship between local skin temperature and cutaneous perfusion during scalp cooling PhysiolMeas; 28(8)829-39.

9- Rosdahl, C., \&Kowalski, M., (2008): text book of basic Nursing, $9^{\text {th }}$ ed., London, Lippincott Co., pp 295-300.

10- Smeltzer,s., Bare, B., (2008):Text book of medical surgical nursing ; $11^{\text {th }}$ ed Philadelphia, Lippinicott, Williams\& Wilkins co.,pp;17121735.

11- Susan, C. \& Candice, K. (2013): Medical Surgical Nursing (concepts \&practice), Care of women with reproductive disorder $2^{\text {nd }}$ edElsevier co., pp; 927 -939.

12- Duffy，S.W..Tabar， L，Olsen, A.H., et al. (2010): Absolute numbers of lives saved and over diagnosis in breast cancer screening, from a randomised trial and from the Breast Screening Program in England. Journal of Medical Screening 17(1): 25-30.

13- feuerstein, M, Gam, P,A, (2011): Quality head care for cancer survivors. In M. Feuerstein, PA. Ganz (eds) Health Services for Cancer Survivors. $\mathrm{S}$ p ringe $\mathrm{r}: \mathrm{Ne}$ w York, p p. 373-85.

14- National Cancer Institute (2011):Targeted Cancer Therapies. National Cancer Institute web-based cancer information, http:// www.cancergov/cancertopics/fact sheet/Tnerapy/targeted (accessed 29 July 2011).

15-Massey C. S. (2004): A multicentre study to determine the efficacy and patient acceptability of the Paxman Scalp Cooler to prevent hair loss in patients receiving chemotherapy. Eur J Oncol Nursing; 8: 121-130.

16- Auvinen, P.K., Mahonen, U.A., Soininen, K.M., Paananen, P.K., Ranta-Koponen,

P.H.,Saavalainen, I.E., et al., (2011). The effectiveness of a scalp cooling cap in preventing chemotherapy-induced alopecia. Tumori 96, 271e275.

17- El-madbouh, G., (2010):Efficacy of scalp cooling on the prevention of chemotherapy-induced alopecia in breast cancer patient undergoing 
EFFICACY OF SCALP COOLING ON THE PREVENTION OF etc...

adjuvant chemotherapy.

Unpublished Master thesis.

Faculty of Nursing, Menoufyia University, pp 46-48.

18- El-saka, R., (2008): Scalp cooling efficacy in reducing Anthracycline-induced alopecia and its psychosocial impact in breast cancer patients. Unpublishe Master thesis. Faculty of medicine, Alexandria University, pp 15-17.

19- Katsimbri P, Bamias A, Pavlidis N (2000): Prevention of chemotherapy-induced alopecia using an effective scalp cooling system. Eur J Cancer, 36: 766-771.

20- Hurk van den, C.J.G., Sande van de, M.A.E., Breed, W.P.M., Nortier, J.W.R.(2013):Adjuvant chemotherapy in breast cancer patients without and with scalp cooling: very low incidence of scalp skin metastases in retrospective studies. 2013; (submitted)

21- Lemenager M, Lecomte S, Bonneterre ME, Bessa E, DaubaJ, Bonneterre J (1997): Effectiveness of cold cap in the prevention of docetaxel-induced alopecia. Eur J Cancer, 33: 297300.

22- Kargar,M, Sarvestani, RS., Khojasteh,HN., Heidari,MT., (2011): Efficacy of penguin cap as scalp cooling system for prevention of alopecia in patients undergoing chemotherapy Journal of advanced nursing 67 (11), 24732477

23- Peck HJ,Mitchell H, Steward AL(2000):Evaluating the efficacy of scalp cooling using the Penguin cold cap system to reduce alopecia in patients undergoing chemotherapy for breast cancer. Eur J OncolNurs, 4: 246-248.

24- Grevelman E.G and Breed W.P.M. (2005): Prevention of chemotherapy induced hair loss by scalp cooling. Ann Oncol; 16: 352358.

25- Edelstyn GA, MacDonald M, MacRae KD.(1977): Doxorubicin-induced hair loss and possible modification by scalp cooling. Jul 30;2(8031):253-254.

26- Parker R (1987): The effectiveness of scalp hypothermia in preventing cyclophosphamideinduced alopecia. OncolNurs Forum 14:49-53.

27- Macduff C,Mackenzie T, HutcheonA,Melville L, Archibald H (2003): The effectiveness of scalp cooling in preventing alopecia for patients receiving epirubicin and docetaxel. Eur J Cancer Care, 12: 154-161 